\title{
O POTENCIAL CONTAMINANTE DO DESCARTE INCONGRUENTE DE BLISTER \\ FARMACÊUTICO: SOLUÇÕES AMBIENTAIS.
}

\section{THE CONTAMINANTS POTENTIAL OF INCONGRUOUS DISCART OF PHARMACEUTICALS BLISTERS: ENVIRONMENTAL SOLUTIONS.}

\author{
Alan Rodrigo Sulareviscz', Bianca Sczezepanski ${ }^{1}$, Leslyn Aparecida da Silva ${ }^{1}$, \\ Maoma Vitoria Amarante Calderari ${ }^{1}$, Ohanna Christine Haile ${ }^{1}$, Priscila Arcoverde \\ Wosiack $^{2}$, Vanessa Barbosa Bobek ${ }^{3^{*}}$
}

1 - Acadêmico de Farmácia, Centro de Ensino Superior dos Campos Gerais

2 - Docente Mestre Faculdade de Farmácia, Centro de Ensino Superior dos Campos Gerais, Ponta Grossa - Paraná

3 - Docente Doutora Faculdade de Farmácia, Centro de Ensino Superior dos Campos Gerais, Ponta Grossa - Paraná

\section{RESUMO:}

Esta revisão literária tem o intuito de investigar o descarte dos insumos residuais farmacológicos, ou seja, os blisters. O material em questão é comumente obtido através de medicamentos sólidos, tendo como finalidade promover a estabilidade do fármaco e garantizar a eficácia ao longo do tempo. Os blisters, vulgarmente conhecida por cartelinhas de medicamentos, são materiais industrializados que contém, basicamente alumínio, aclar e o pvc. O alumínio confere a proteção deste e dá-lhe a praticidade para retirar o medicamento, enquanto o aclar e o pvc são materiais maleáveis e resistentes que fazem o revestimeno. De acordo com a pesquisa comunitária realizada nas cidades de Castro, Piraí do Sul e Ponta Grossa, foi possível verificar que, independente da faixa etária, escolaridade e situação habitacional, a população desconhece a origem desse material, além do seu descarte adequado. Com isso, o propósito deste artigo tem o quesito de instigar lesgilações vigentes e propostas para reverter uma problemática que pouco preocupa.

Palavras-chave: Cartelinha de medicamentos. Descarte de blisters. Contaminação de produtos farmacêuticos.

\section{ABSTRACT:}

This literature review aims to investigate the disposal of residual pharmacological inputs, the blisters. The above material is commonly obtained through solid medicaments, for the purpose of promoting drug stability and ensuring efficavy over time. The blisters, commonly know as drug cartels, are industrialized materials that contain, basically alumonium, clarify and pvc. The aluminium confers the protection and gives it the practicality to withdraw the medicament, while the aclar and pvd are soft and resistent material that make coating. According to the community research in the cities of Castro, Piraí do Sul and Ponta Grossa, it was possible to verify that, regardless of age, schooling and housing situation, the popularion in unaware of the origin on this material, besides its proper disposal. After that, the purpose of this article is to instigate current legilations and proposals to revert a problematic that has little concern.

Keywords: Drug label. Discard of blisters. Contamination of pharmaceutical products. 


\section{INTRODUÇÃO}

A contaminação ambiental acometida por resíduos farmacêuticos, embora não seja demonstrada tanta preocupação, é um dos grandes problemas urbanos e capitalistas no mundo. Através da produção em grande escala de medicamentos, para oportunizar uma melhor qualidade de vida a população, são produzidos também o seu conteúdo de revestimento, denominado blister. As cartelinhas, coloquialmente ditas, são um dos materiais que mais fornecem riscos, seja a vida animal ou a vida vegetal, pois contém dois materiais extremamente poluentes, são eles o plástico pvc e o alumínio (HERNÁNDEZ, SD; MELLO, 2007; ROSO; FOLETTO, 2014).

É de relevante importância questionar a implementação de normativas que determinem o gerenciamento de resíduos, que objetive amenizar os riscos a saúde comunitária e ao meio ambiente, causadas pelo descarte inadequado. De acordo com a resolução RDC no 306 da ANVISA, de 7 de dezembro de 2004, "Resíduos químicos que apresentam ricos a saúde ou ao meio ambiente, quando não forem submetidos a processo de reutilização, recuperação ou reciclagem, devem ser submetidos a tratamento ou disposição final específicos.". Sem embargo, como constra na mesma resolução, "As embalagens e materiais contaminados por substâncias caracterizadas no item 11.2 deste Regulamento devem ser tratados da mesma forma que a substância que as contaminou." (MELLO, 2007; ROSO; FOLETTO, 2014).

Perante as diretrizes, pode-se observar o ponto de vista a respeito do descarte de medicamentos, não sendo estendida da mesma forma para a embalagem onde nela estão contidas antibióticos, anticonceptionais, antirretrovirais, analgésicos, dentre outros. Cabe então a uma questão científica voltada a possibilidade de contaminação ambiental ocasionada pelos resíduos deixados nas embalagens e pelo material propriamente dito, segundo sua composição (BALBINO; BALBINO, 2011).

No Brasil, a legislação fornecida pelo CONAMA - Conselho Nacional do Meio Ambiente - promove o incentivo a separação dos materiais, segundo a sua matéria-prima. No entanto, pertante o projeto de Lei № 7.064 , de 2014, aprovado pela Câmara dos Deputados, ocorre a determinação da disponibilidade das farmácias comerciais receber todos os resíduos de medicamentos, onde deverão ser destiandos ao fabricante, para seu destino fina adequado. (ROSO; FOLETTO, 2014).

Contudo, como princípio para uma investigação científica ambiental, a relação entre o potencial contaminante das cartelinhas de medicamentos e a possibilidade de reciclagem são fundamentos para visar, possivelmente, uma nova constituição nacional, determinando a 
todos os fabricantes receber os resíduos gerados, além do medicamento, a fim de encontrar meios sugestivos de reincorpoação. Através dos dados demográficos obtidos, nota-se a falta de preocuação da sociedade ocasionada pela própria escassez de embasamento sobre o assunto. Tal problemática pode estar relacionada não somente a mídia como um todo, porém uma falha da comunidade farmacêutica. Por isso, há um interesse incessante em buscar intermediar o custo desses materiais com a biodisponibilidade do fármaco, propondo o desenvolvimento de blisters biodegradáveis (HERNÁNDEZ, SD; MELLO, 2007).

\subsection{Constituição material dos blisters e seu potencial contaminante}

Por longos anos levou-se em consideração a utilização de vidrarias no armazenamento de medicamentos, juntamente com algodão, referido como material de apoio. Durante a década de 60 , se estendeu um diversificado modo de introdução dos medicamentos nas embalagens, que, antes colocadas em vidro, passaram a ser dispostas em cartelas, onde estas eram produzidas e revestidas com materiais com propriedades químicas que garantiam a estabilidade e a qualidade dos medicamentos (DUTRA, 2013; BALBINO; BALBINO, 2011).

A utilização de materiais diferenciados no armazenamento dos fármacos, teve de efeito, melhoras referente ao acondicionamento em relação à estabilidade. De certa forma, acarretou menos riscos à saúde e o ambiente, pois as ferramentas utilizadas eram de caráter reciclável. A superfície completa da embalagem consiste em um componente de grande utilidade em processos químicos, o alumínio. Derivado principalmente da bauxita, um minério com caráter argiloso, porem com plasticidade. (Figura 1).
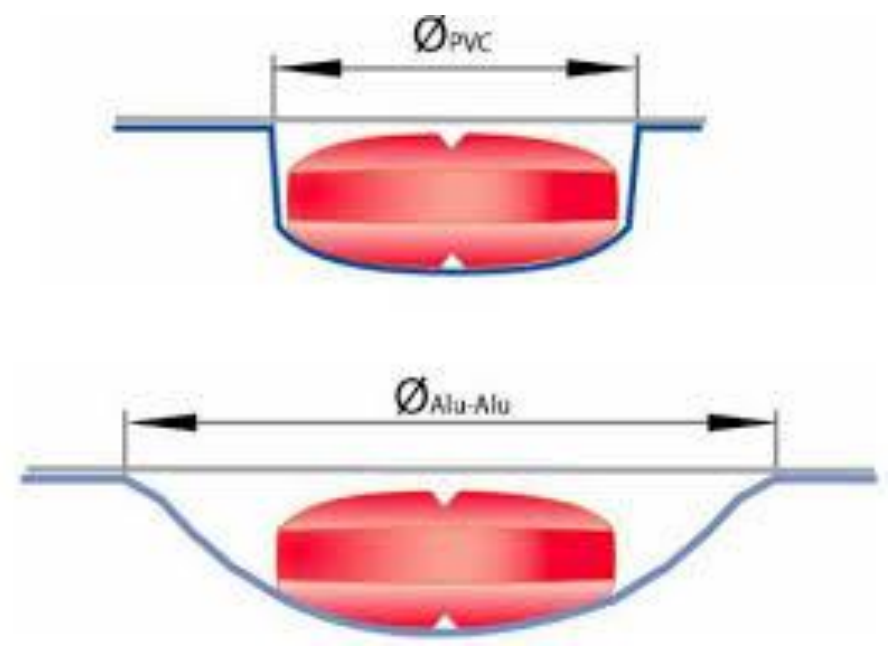

Fonte: FERREIRA; PEREIRA, 2016.

Figura 1. Representação do blister farmacêutico. 
Uma das substâncias bastante comum a constituição dos blisters é o alumínio. Na sua forma in natura é encontrado em rochas e minérios. Embora sejam recomendados pela sua estabilidade há controvérsia por não ser degradado naturalmente. Quando em contato com a saúde animal, pode ocasionar riscos tóxicos a nível celular, a exemplo a inibição de multiplicação dos eritrócitos na medula óssea e doença de Alzheimer (MELLO, 2007).

O alumínio, com densidade de $2.700 \mathrm{~km} / \mathrm{m}^{3}$, possui propriedades físicas e químicas relativamente desejáveis, trazendo benefícios à conservação do fármaco no acondicionamento. Pode-se ressaltar que esse metal reage com extrema rapidez com o oxigênio, anulando a passagem deste e a quantidade de vapor de agua atmosférica que entra na embalagem (MELLO, 2007; PEREIRA; FERREIRA, 2016).

O pvc/pvdc (cloreto de polivinila) também compõe o blister, uma vez que são uma espécie de plástico de revestimento mais avançado que possuem duas camadas que criam uma barreira contra a umidade e gás. Já o pvdc é um copolímero extremamente parecido com o pvc, usado como película final, dando uma vedação no produto (PEREIRA; FERREIRA, 2016).

É constituído basicamente de PVC/PVDC e Aclar, que são produtos atóxicos e facilmente temoformados, com o intuito de proteção contra oxigênio, umidade e até mesmo contra a luz. O pvdc, embora também possui características parecidas com o pvc, ele pode passar pelo processo de reciclagem energética e transformar o plástico em energia, mas 0 Brasil ainda não usufrui desse recurso (HERNÁNDEZ, SD; PEREIRA; FERREIRA, 2016).

Segundo o Instituto Brasileiro do Meio Ambiente (IBAMA), os plásticos, como o PVC, levam em torno de 200 a 600 anos para se decompor completamente na natureza. E apesar do PVC ter vários destinos, o mais adequado seria a reciclagem correta desse material, pois temos outro meio, a incineração e nesse caso, o PVC, por ser um composto formado por substâncias cloradas, nesse processo ele desprenderá o cloro e formará outros compostos clorados, como a dioxina, que é altamente tóxica (HERNÁNDEZ, SD; MELLO, 2007).

O aclar® 88A, um policlorotrifluoroetileno, é uma espécie de plástico feito por termoformagem (prensagem) que consiste na fabricação de um componente a partir de folhas de plástico pré-aquecidas, viabilizando aplicações de revestimento e película. Esse copolímero, tem estabilidade dimensional, resistência química, flexibilidade e deve-se salientar que anula a passagem de umidade. (HERNÁNDEZ, SD; MELLO, 2007; PEREIRA; FERREIRA, 2016)

Apesar de ser formado por substâncias de caráter reciclável, com métodos muito 
práticos, apenas separando os dois componentes do blister e encaminhando a lugares especializados para efetuar a sua reciclagem pode contribuir para minimizar a contaminação. No entanto, parte desse problema ocorre devido a falta de preocupação social quanto aos problemas que o descarte inadequado pode acarretar em danos ambientais (PEREIRA; FERREIRA, 2016).

\subsection{Presença e resquísios de medicamentos}

A Agência Nacional de Vigilância Sanitária (ANVISA) relata o conceito de medicamento como sendo todo "produto farmacêutico, tecnicamente obtido ou elaborado, com finalidade profilática, curativa, paliativa ou para fins de diagnóstico". Portanto, trata-se de um produto sólido ou líquido composto por um princípio ativo, passível de descarte, tornando-se, assim, um resíduo (DUTRA, 2013).

Desde a década de 70 analisa-se a presença de fármacos em ambientes aquáticos. Fármacos estes, descritos como o princípio ativo que causa a ação biológica e inclusive o efeito tóxico. Estudos realizados mostram resíduos de medicamentos em diversas partes do mundo. Segundo uma investigação realizada em 2008, pela Associated Press (AP), uma agência americana de notícias, verificou-se que a água potável, de aproximadamente 41 milhões de pessoas nos Estados Unidos, está contaminada com resíduos de fármacos (HOPPE; ARAÚJO, 2012; RODRIGUES, 2009).

Exames laboratoriais revelam a presença de, no mínimo, 63 medicamentos diferentes e seus derivados, principalmente anticonvulsivantes, antibióticos e ansiolíticos. De acordo com a Resolução CONAMA nº 358/05, os resíduos de medicamentos devem ter uma atenção e descarte especiais, já que se encaixam como resíduos perigosos por apresentarem risco à saúde humano e ao meio ambiente. Até mesmo os medicamentos consumidos são eliminados no ambiente, já que as excreções humanas são desprezadas em rios e mares (HOPPE; ARAÚJO, 2012; RODRIGUES, 2009).

No Brasil, devido às condições precárias do sistema de gerenciamento de resíduos, não há estatísticas precisas a respeito do número de geradores, nem da quantidade de resíduos de serviço de saúde gerada diariamente. Essa contaminação ocorre quando os serviços de saúde, tatuagens, acupunturas e similares desprezam de forma inadequada seu lixo produzido (HERNÁNDEZ, SD; MELLO, 2007; ROSO; FOLETTO, 2014).

Os blisters incinerados, como a maioria é de plásticos, principalmente os de PVC e PVCD, soltam uma substância tóxica e teratogênica, chamada dioxina $\left(\mathrm{C}_{12} \mathrm{H}_{4} \mathrm{Cl}_{4} \mathrm{O}_{2}\right)$, 
conhecida por seu fator cancerígeno. Então, os blisters, se descartado de maneira incorreta, leva anos para degradar-se, dependendo de sua natureza, plástico ou vidro, e, mesmo incinerado, causa contaminação devida à estrutura do plástico (HOPPE; ARAÚJO, 2012).

Os lixos produzidos são classificados de acordo com sua toxicidade e periculosidade quanto ao meio ambiente e ao ser humano. Os medicamentos se encaixam nos componentes químicos. Os resíduos produzidos causam poluição ambiental e provocam um desequilíbrio ambiental natural. Diante desses fatos, torna-se importante a disseminação de informação à comunidade para com os riscos para promover a melhoria de vida e saúde e disponibilizando um ambiente saudável e sustentável, já que a legislação vigente se aplica somente à empresas e ambientes de saúde e não à população em geral. (HERNÁNDEZ, SD; MELLO, 2007; ROSO; FOLETTO, 2014).

\subsection{Empresas coletam blisters para reaproveitamento}

No mercado Brasileiro, existem atualemente duas empresas que se dispõem a coletar esses resíduos. A Sanofi é uma coporação industrial que além de produzir medicamentos comuns ao cotidiano, também possui diretrizes que determinam o destino dos resíduos industriais, sendo a reciclagem ou a incineração. Enquanto isso, a eCycle, empresa que viabiliza o contato direto via on-line para a coleta de recicláveis.

\subsubsection{Sanofi}

A empresa Sanofi trata de diretrizes que priorizam como deverão ser destinados os resíduos acumulados ou coletados. Primordialmente, parte pela reciclagem, por conseguinte a incineração sem a recuperação de energia e em último caso o aterro sanitário. Este método está imposto pela própria, no entanto antende aos padrões estabelecidos (SANOFI, 2017).

\subsection{2 eCycle}

A conscientização parte dos interesses pelas relações entre empresas, indivíduo e meio ambiente. Com base nos princípios de valorização econômica, possibilita a promoção de um habitat mais saudável, empregando práticas sustentáveis. Propondo a redução de 
impactos ambientais, a eCycle tem como fundamento a reversão do alto consumo de energia, preocupações hidológicas e aquecimento global, biodiversidade, contaminações e impactos ambientais causados (HERNÁNDEZ, SD).

\subsection{Possíveis métodos de reciclagem}

Em ênfase, os resíduos sólidos possuem classificações quanto a seus riscos num todo, viabilizando duas classes, as que causam perigo (A) e as que não são nocivas (B). $A$ implantação da logística reversa é o instrumento de desenvolvimento econômico e social caracterizado pelo conjunto de ações, procedimentos e meios destinados a viabilizar a coleta e a restituição dos resíduos sólidos ao setor empresarial, para reaproveitamento, em seu ciclo ou em outros ciclos produtivos, ou outra destinação final ambientalmente adequada (MELLO, 2007; ROSO; FOLETTO, 2014).

Os resíduos da cartela de comprimido são classificados então, de acordo com a sua periculosidade, nas quais são apontados como não agravantes ao meio ambiente, se por ventura não terem o descarte errôneo (DUTRA, 2013; BALBINO; BALBINO, 2011).

Um dos métodos de reciclagem para o alumínio, componente essencial do blister, é o processo de fundição, onde após o metal ter sido separado e recolhido pela coleta seletiva, ele passa a ser separado das impurezas que o constituem e as que se misturaram durante a coleta. Em seguida ele é triturado em dimensões pequenas com a finalidade de ser derretido a $700^{\circ} \mathrm{C}$ (HOPPE; ARAÚJO, 2012; RODRIGUES, 2009).

Após a fundição, o alumínio passa do estado solido para liquido, que, acaba sendo transformado em chapas que são comercializados em indústrias que produzem certos tipos de embalagens. Dessa forma o alumínio volta ao ciclo produtivo (HOPPE; ARAÚJO, 2012; RODRIGUES, 2009).

Deve-se destacar a presença de outros componentes na cartela, o PVC e o PVCD. O primeiro possui mais de um modo de reciclagem, onde o mais conhecido é o que está presente em quase todos os tipos de material reciclável, o processo mecânico tradicional. Este consiste na transformação de um produto sem utilidade em outro feito para consumo (FABRIS; NETO; TOALDO, 2010; RODRIGUES, 2009).

O processo pelo qual esse tipo de plástico passa, consiste na separação e trituração em pequenos fragmentos. Em seguida, são lavados e tratados para que ocorra a eliminação de todas as impurezas. Por fim, são novamente reutilizados, onde as embalagens que no caso, os blisters são formadas após o tratamento em processos de 
drenagem (FABRIS; NETO; TOALDO, 2010; RODRIGUES, 2009).

Uma das outras formas mais difundidas é a reciclagem química, que consiste na quebra das cadeias de polímeros com a finalidade de obter os óleos e gases presentes no pvc. O processo Vinyloop®, separa outros componentes presentes no pvc. Esse processo tem por finalidade diluir do pvc, os resíduos com auxílio de um solvente, onde após a moagem, segregação e secagem, são literalmente liberados após tratados (HOPPE; ARAÚJO, 2012; FABRIS; NETO; TOALDO, 2010; RODRIGUES, 2009).

Embora a reutilização desses polímeros seja indispensável na comercialização de produtos novos, eles também podem estar presentes na recuperação de energia, pois o pvc pode ser usado em incinerador por aderir cloro na sua composição. Em contrapartida, os gases que são liberados também irão precisar de um tratamento (RODRIGUES, 2009).

\subsection{Influência dos meios de comunicação para disseminar o conhecimento e precaver os cuidados ao meio ambiente}

Segundo o artigo "Influências dos meios de comunicação no conhecimento", publicado por José Manuel Moran, para obter conhecimento é necessário o tato, a visão e a audição, já que cada indivíduo se familiariza ao significados e objetos com o raciocínio (MORAN, 1994).

Os meios de comunicação buscam, com o passar dos anos, adaptar-se e aperfeiçoar os seus métodos de linguagem conceitual, para causar impactos não tão somente psicológicos, mas também emocionais. A tarefa multilinguística do meio globalizado intefere de modo impactante a sociedade que, por dependência, utiliza dos recursos tecnológios para obter informações (MORAN, 1994; FABRIS; NETO; TOALDO, 2010).

O conhecimento é definido como qualquer informação armazenada na memória, mas quando o sujeito é o consumidor, as informações operadas no mercado são denominadas como desconhecimento do consumidor, sendo em relação às características dos produtos e serviços, os locais onde podem ser comprados e a maneira de usá-los (FABRIS; NETO; TOALDO, 2010).

Algumas relevâncias, para isso, devem-se pela propagação de métodos de coleta seletiva, reaproveitamento de materiais, reciclagem artesanal. Com isso, mostra-se que as informações obtidas são de significativo impacto na atitude sustentável da comunidade, desde que haja um conhecimento prévio (MORAN, 1994). 
Evidentemente, os meios de comunicação são de fundamental importância para disseminar informações a respeito dos impactos ambientais causados pelo decarte errôneo de diversos materiais. Diante deste completo sistema, diversas abordagens surgem como propósito explicativo, a exemplo da aprendizagem social, a qual prevê uma socialização como resultado das forças do meio ambiente para com a humanidade. Os resultados são perceptíveis, cuja explicação deve-se ao entendimento das influências comportamentais e atitudes, como a propaganda de forma explícita e vulgar (MORAN, 1994; FABRIS; NETO; TOALDO, 2010).

\subsection{Desenvolvimento de blisters biodegradáveis e suas vantagens lucrativas para as indústrias farmacêuticas}

Para este estudo, diante das informações apresentadas até o instante, a proposta de solução mais curiosa é a elaboração industrial de blisters com potencial biodegradáveis, sem que afetem instantaneamente a estabilidade do fármaco e a sua biodisponibilidade.

No Brasil, atualemente não há venda de medicamentos contidos em revestimentos biodegradáveis, apenas o convencional, conforme citado. No entanto, pesquisas comprovam a identificação de novas matérias sustentáveis, sendo esta a base de polímero poliácido lático (DUTRA, 2013; BALBINO; BALBINO, 2011).

De acordo com o estudo realizado por L. F. Miranda et. a. Universidade de Mackenzie, esse polímero tem grande utilidade como biodegradante, podendo ser facilmente extrudado ou moldado. Durante o processo de fabricação, é necessário tomar cuidados, pois pode apresentar retenção de umidade e rápido aumento da temperatura como consequência de agentes externos (DUTRA, 2013; BALBINO; BALBINO, 2011).

O desenvolvimento dos polímeros deve ser explorado pela indústria farmacêutica como um aliado para a comercialização de medicamentos, como preocupação ambiental. Neste caso, a modulagem de um blíster biodegradável, com enfoque nos polímeros, são capazes de substituir aqueles convencionais, pois apresentam alta dureza e capacidade de rago iguais entre si. Entretanto, é necessário acompanhar a estabilidade de cada formulação medicinal para estudar casos de variância entre suas propriedades terapêuticas (DUTRA, 2013).

As vantagens para a aderir aos blisters biodegradáveis vão desde a redução de impactos ambientais pela sua autodeterioração, redução de intoxicação no organismo, conscientização do uso racional de medicamentos e o favorecimento da cultura do cuidado 
e atenção ao consumo de medicamentos, eficiência do processo produtivo com a responsabilidade ampliada pelo resíduo pós consumo, melhora a eficiência da coleta seletiva, oportunidade de gerar novos negócios, a possibilidade de diminuir gastos para com a obtenção de matéria prima no processo de desenvolvimento dos blisters (TOALDO, 2010).

\section{METODOLOGIA}

O presente artigo trata-se de uma pesquisa científica bibliográfica narrativa e estudo de caso nas cidades de Castro, Piraí do Sul e Ponta Grossa, no estado do Paraná. Foi realizada uma busca de artigos nas bases Google Schoolar, Scielo, e portais do sistema público do Brasil, na língua portuguesa, utilizaram-se as seguintes palavras-chave: cartelinha de medicamentos, descarte de blisters, contaminação de produtos farmacêuticos.

\section{RESULTADOS E DISCUSSÃO}

Para o estudo, foram distribuídos 200 formulários a comunidade em geral, nas cidades de Castro, Piraí do Sul e Ponta Grossa, no estado do Paraná. Os entrevistados foram procurados a partir dos 17 anos de idade, contendo informações como: Faixa etária (jovens de 17-30 anos, adultos de 30-60 anos ou melhor idade acima de 60 anos de idade), escolaridade (ensino fundamental, médio ou superior), moradia (interior, bairro ou centro), hábito de coleta seletiva, local de descarte dos blisters e se já receberam orientações a respeito do descarte adequado.

Castro é uma cidade do interior do Paraná, possui 67 mil habitantes, segundo dados do IBGE 2010. Piraí do Sul, município vizinho, contém aproximadadente 25 mil habitantes. Ponta Grossa, cidade que possui mais de 340 mil habitantes.

Baseado nos resultados demográficos obtidos, conforme a tabela abaixo, a faixa etária nas cidades de interior está composta, grande parte, por adultos, isto é, com idade de 30 a 60 anos, sendo a escolaridade representada pelo ensino médio (E.M) e residentes dos bairros que circundam o centro da cidade. No entanto, a cidade de Ponta Grossa, foi representada com maior faixa etária para jovens, de 17 a 30 anos de idade, com escolaridade a nível superior, apresentando apenas residência nos bairros. (Tabela 1). 
Tabela 1 - Dados demográficos coletados nas cidades pesquisadas.

\begin{tabular}{|c|c|c|c|c|c|c|c|c|c|}
\hline \multirow{3}{*}{ Cidades } & \multicolumn{9}{|c|}{ RESULTADOS DOS DADOS DEMOGRÁFICOS (\%) } \\
\hline & \multicolumn{3}{|c|}{ Faixa etária } & \multicolumn{3}{|c|}{ Escolaridade } & \multicolumn{3}{|c|}{ Moradia } \\
\hline & $17-30$ & $30-60$ & $>60$ & E.F & E.M & E.S & Interior & Bairros & Centro \\
\hline Castro & $29 \%$ & $47 \%$ & $24 \%$ & $7 \%$ & $72 \%$ & $21 \%$ & $9 \%$ & $67 \%$ & $24 \%$ \\
\hline Piraí do Sul & $20 \%$ & $66 \%$ & $14 \%$ & $43 \%$ & $32 \%$ & $25 \%$ & $12 \%$ & $69 \%$ & $19 \%$ \\
\hline Ponta Grossa & $51 \%$ & $37 \%$ & $12 \%$ & $12 \%$ & $43 \%$ & $45 \%$ & $9 \%$ & $63 \%$ & $28 \%$ \\
\hline
\end{tabular}

Fonte: $\mathrm{O}$ autor.

A pesquisa ambiental realizada teve como principal objetivo um breve diagnóstico da preocupação comunitária sobre o descarte e o destino das cartelinhas de comprimidos. Como pode ser avaliado, nas cidades de Castro e Piraí do Sul, a população não tem o hábito de devolver as farmácias, se comparado ao resultado da cidade de Ponta Grossa, onde $77 \%$ dos entrevistados realizam a devolução dos resíduos a alguma farmácia local.

No entanto, pode-se dizer que aqueles, cujo hábito é descartar os blisters na própria residência, estão separando os materiais através da coleta seletiva, ou seja, realizam a divisão entre os materiais orgânicos daqueles que não poderão ser recicláveis e os resíduos recicláveis.

Embora na cidade de Ponta Grossa a marioria dos entrevistados recebeu orientações sobre o descarte adequado, nas cidades do interior dos Campos Gerais não há a disseminação sobre os métodos de descarte, conforme dos dados descritos na tabela 2.

Tabela 2 - Resultados da pesquisa ambiental realizada nas cidades

\begin{tabular}{l|cc|ccc|cc}
\hline \multirow{2}{*}{ Cidades } & \multicolumn{6}{|c|}{ RESULTADOS DA PESQUISA AMBIENTAL (\%) } \\
\cline { 2 - 9 } & \multicolumn{2}{|c|}{ Descarte de blister } & \multicolumn{3}{c}{ Coleta seletiva } & \multicolumn{2}{c}{ Orientações } \\
\cline { 2 - 9 } & Farmácia & Residência & Sempre & Raramente & Nunca & Recebeu & Não \\
\hline Castro & $20 \%$ & $80 \%$ & $70 \%$ & $11 \%$ & $19 \%$ & $26 \%$ & $74 \%$ \\
Piraí do Sul & $16 \%$ & $84 \%$ & $64 \%$ & $14 \%$ & $22 \%$ & $43 \%$ & $57 \%$ \\
Ponta Grossa & $77 \%$ & $23 \%$ & $52 \%$ & $27 \%$ & $21 \%$ & $68 \%$ & $32 \%$ \\
\hline
\end{tabular}

Fonte: $O$ autor. 
Comparando os entrevistados da cidade de Ponta Grossa e de acordo com o intuito da pesquisa, é possível afirmar que a causa para apresentar, nesta cidade, uma melhor orientação comunitária sobre a importância de descartar adequadamente os resíduos, além disso, onde devem ser depositados. Tal resultado é obtido através de uma legislação que está sendo praticada neste município, determinando as farmácias comerciais e públicas receber os medicamentos sem utilização, enquanto oportuniza para muitos depositar também os resíduos, tal como os blisters.

Contudo, nas cidades de interior não há qualquer orientação, ou então mínima preocupação por parte dos profissionais do setor de saúde e dos habitantes. As farmácias encontradas não disponibilizam a coleta dos resíduos e por conta disso, as pessoas são obrigadas a despejá-los na própria residência.

De acordo com a pesquisa realizada e com o gráfico apresentado, pode-se observar que a falta de informações para realizar o descarte correto dos blisters não está diretamete relacionado a população como um todo, mas a questão da comunicação e distribuição de informações.

Numa totalidade de 600 pessoas entrevistadas, somatória entre todas as cidades, é possível definir que embora algumas pessoas recebam orientações, independente da sua classificação demográfica, muitas mostram preocupação para com o meio ambiente.

Embora, muitas dessas pessoas, realizam apenas o decarte a rsidência, sem a convicção do destino dos blisters, podendo ser ou não a reciclagem, aterros ou até mesmo expostos ao meio ambiente, acarretando problemas ambientais.

Figura 2 - Gráficos demonstrativos em percentuais dos resultados obtidos.

\section{Faixa etária}

\section{Escolaridade}

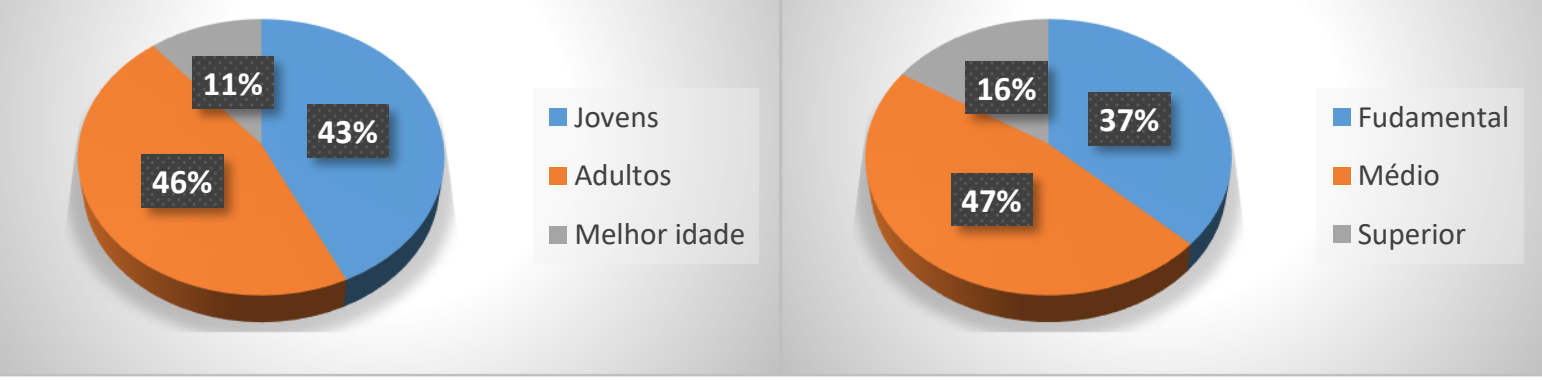


Moradia

\section{Modo de descarte}
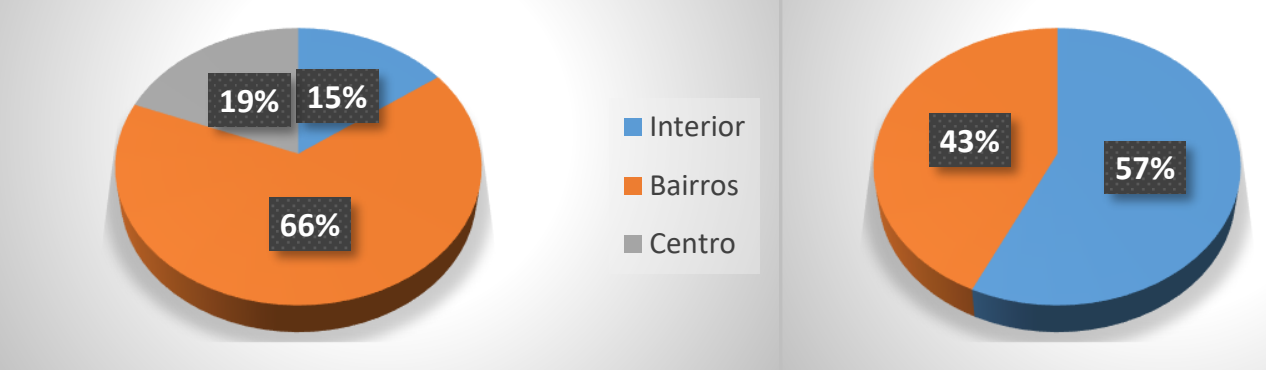

- Residência

n Farmácia

\section{Coleta Seletiva}

Orientações
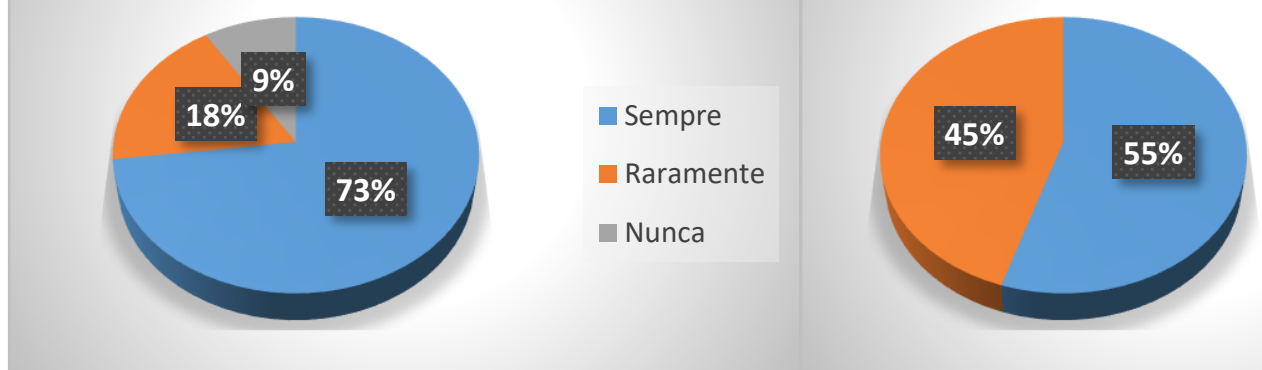

Recebeu

orientações

- Não recebeu orientações

Fonte: O autor.

Embasado no projeto de lei $n^{\circ} 7.064$, de 2014 , Art. $3^{\circ}$, "As farmácias, drogarias e distribuidoras de medicamentos disponibilizarão espaços adequados em seus estabelecimentos para receberem, em devolução, os medicamentos com a data de validade vencida ou que estejam deteriorados e inservíveis".

Sendo que ainda é determinado no Art. 50, "Após a devolução dos medicamentos a que se refere o Art. $3^{\circ}$ desta lei, os medicamentos serão acondicionados em embalagens separadas de outros tipos de resíduos e encaminhados para sua destinação final adequada, observadas as disposições legais". Através disso, mostra-se que em algumas localidades do país não ocorre a fiscalização da coleta de medicamentos (ROSO; FOLETTO, 2014).

Ainda, na mesma lei, o Art. 6o remete a seguinte determinação "Após a devolução dos medicamentos a que se refere o Art 4ํㅡㄹ desta lei, os medicamentos serão encaminhados aos seus fabricantes e/ou distribuidores, sem qualquer ônus para as farmácias e drogarias". Portanto, é dever das farmácias oferecer o serviço de coleta gratuitamente, assim, como também, não sendo sobrecarregados como responsáveis (ROSO; FOLETTO, 2014).

Quanto a coleta dos medicamentos, ainda rege, a mesma lei sobre a orientação aos fabricantes quanto as informações a serem distribuídas, sendo esta uma 
responsabilidade social. No Art. 10, "O poder público, os fabricantes e/ou distribuidores de medicamento são responsáveis pela realização periódica de amplas campanhas educacionais nos meios de comunicação, incluindo os meios eletrônicos, visando a esclarecer a população sobre os riscos causados pelo armazenamento domiciliar de medicamentos e pelo descarte inadequado dos medicamentos vencidos ou deteriorados, informando sobre importância de procurar os locais onde estes medicamentos podem ser devolvidos em segurança. " Parágrafo $3^{\circ}$, "As embalagens dos medicamentos devem conter os dizeres: "Não armazene medicamentos em casa. Leve-os à farmácia mais próxima. O uso, armazenamento e descarte inadequado de medicamentos causam danos à saúde e ao meio ambiente." (ROSO; FOLETTO, 2014).

\section{CONCLUSÃO}

Os blisters são materiais de extrema importância para a comercialização de medicamentos, pois agregam valor ao mesmo, por possuir propriedades físico-químicas que interferem na estabilidade. Dentre os componentes encontrados, tais como o alumínio e o Aclar ou PVC/PDVC, não interferem de modo direto a contaminação ao meio ambiente. No entanto, seu descarte incorreto acarreta problemas ambientais e considerável toxicidade a vida animal.

Através do embasamento científico, pode-se considerar que este material tem capacidade reciclável, após a descontaminação dos resíduos presentes. Sem embargo, pode-se fomentar que é importante a implementação de legislação sanitária que determine as redes comerciais e públicas disponibilizar a coleta desses resíduos, já que uma vez ofertado, deve ser de responsabilidade da logística oferecer a coleta adequada. Com a elaboração de uma nova lei, resultará a facilidade de reunir todos os resíduos e destiná-los a uma entidade responsável pela reintegração ao meio.

De acordo com a pesquisa realizada em pequena proporção, a mesma foi satisfatória para pontuar as falhas comunicativas relacionadas ao descarte inadequado cas cartelinhas de comprimidos. Neste caso, pode-se notar que, independente da classificação, há um grande desfalque de orientações. Deve-se salientar que é de responsabilidade dos órgãos de saúde e do próprio governo dispor na mídia a problemática, os métodos de coleta, métodos de separação e possível reciclagem.

Outrora, uma nova era biotecnológica visa o desenvolvimento e aperfeiçoamento de blisters a uma estrutura molecular biodegradável, que possa em poucos anos ser 
degenerada pela ação do tempo, da temperatura e do ar. Para isso, é imporante salientar as indústrias que produzem os medicamentos uma nova visão ambientalista sobre os mesmos. Contudo, é relevante concretizar os estudos de estabilidade, para que oportunizem um produto de renomada qualidade a população.

O desenvolvimento de uma nova metodologia de criação dos blisters poderá, a curto prazo, trazer um grande investimento maquinofatureiro, mas que em pouco tempo poderá ser recompensado pela economia na obtenção de matéria-prima, se comparado aos convencionais.

\section{REFERÊNCIAS}

BALBINO, E. C.; BALBINO, M. L. C. O descarte de medicamentos no brasil: um olhar socioeconômico e ambiental para o descarte de medicamentos. Ind: Âmbito Jurídico. v. 14, n. 86. Rio Grande, 2011. Disponível em: < http://www.ambitojuridico.com.br/site/index. php?artigo_id=9187\&n_link=revista_artigos_leitura> Acesso 08/06/2017

DUTRA, C. Y. Resíduos de medicamentos, responsabilidade compartilhada, sustentabilidade e uso racional de medicamentos. Núcleo de Regulação e Boas Práticas Regulatórias, Agência Nacional de Vigilância Sanitária. Disponível em: http://www.vigilanciasanitaria. sc.gov.br/index.php/download/category/224-curso-pgrss-2013?download=1133:residuosde-medicamentos > Acesso 01/07/2017

FABRIS, C.; NETO, P. J. S.; TOALDO, A. M. M. Evidências empíricas da influência da família, mídia, escola e pares nos antecedentes e no compormisso de separação de materiais para reciclagem. Revista de Administração Contemporânea. v. 14, n. 6, art. 8, p. 1134-1157. Curitiba, 2010

GRUPO SANOFI. Diretrizes e resíduos emitidos pelo grupo sanofi. Disponível em <http://www.rsc.sanofi.com.br/web/planeta/reducao_dos_impactos/residuos>. Acesso $01 / 07 / 2017$

HERNÁNDEZ, M. I. Quais os tipos e opções de decarte de embalagens de medicamentos. eCycle. Disponível em <https://www.ecycle.com.br/component/content/article/67-dia-adia/4984-embalagens-de-medicamentos-quais-sao-os-tipos-existentes-e-descartespossiveis.html>. Acesso 01/07/2017 
HERNÁNDEZ, M. I. Pvdc: conhecas as vantagens e desvantagens desse plástico usado em diversas embalagens. eCycle. Disponível em <http://www.ecycle.com.br/component/ content/article/63-meio-ambiente/4777-pvdc-poli-cloreto-vinilideno-o-que-e-plasticoreciclagem-vantagens-desvantagens-saran-revestimento-filme-embalagem-material-resina -blister-pelicula-laminado-pvc-pet-bopp-atmosfera-modificado-multicamadas-mecanicahalogenios.html>. Acesso 30/06/2017.

HOPPE, T. R. G.; ARAÚJO, L. E. B. A. Contaminação do meio ambiente pelo descarte inadequado de medicamentos vencidos ou não utilizados. Monografias Ambientais REMOA/UFSM. v. 6, n. 6, p. 1248-1262. Rio Grande do Sul, 2012

MELLO, D. R. Embalagens de medicamentos. Agência Nacional de Vigilância Sanitária, Consulta Pública n 81, de 29 de agosto de 2007. Disponível em <http://www4.anvisa.gov .br/base/visadoc/CP/CP\%5B19622-2-0\%5D.PDF>. Acesso 02/07/2017.

MORAN, J. M. Influência dos meios de comunicação no conhecimento. Revista Ciênica da Informação, Instituto Brasileiro de Informação em Ciência e Tecnologia. v. 23, p. 233-238. Brasília, 1994

PEREIRA, D. A. C.; FERREIRA, L. A. Blister farmacêutico: A influência da cor e dos tipos de filmes no acondicionamento de medicamentos. Revista Visão Acadêmica. v. 17, n. 3, p. 91-100. Curitiba, 2016.

RODRIGUES, C. R. B. R. Aspectos legais e ambientais do descarte de resíduos de medicamentos. Dissertação de mestrado Universidade Tecnológica Federal do Paraná. Ponta Grossa, 2009. Disponível em: < http://www.pg.utfpr.edu.br/dirppg/ppgep/ dissertacoes/arquivos/121/Dissertacao.pdf> Acesso 04/07/2017

ROSO, A.; FOLETTO, P. PROJETO DE LEI N. 7.064, DE 2014. Disponível em <http://www.camara.gov.br/sileg/integras/1225104.pdf>. Acesso 04/07/2017.

\footnotetext{
*Autor para correspondência:

Vanessa Barbosa Bobek

vanessabbobek@gmail.com

Centro de Ensino Superior dos Campos Gerais

R. Tomazina, S/N - Olarias, Ponta Grossa - PR, 84025-510

Recebido: 07/09/2020 Aceite: 30/09/2020
} 